\title{
Effect of Supplementation with Calcium Salts of Fish Oil on n-3 Fatty Acids in Milk Fat ${ }^{1}$
}

\author{
E. Castañeda-Gutiérrez, ${ }^{\star}$ M. J. de Veth, ${ }^{\star 2}$ A. L. Lock, ${ }^{\star 3}$ D. A. Dwyer, ${ }^{\star}$ K. D. Murphy, $†$ and D. E. Bauman ${ }^{\star 4}$ \\ *Department of Animal Science, Cornell University, Ithaca, NY 14853 \\ †Virtus Nutrition Inc., Corcoran, CA 93212
}

\begin{abstract}
Enrichment of milk fat with n-3 fatty acids, in particular eicosapentaenoic acid (EPA) and docosahexaenoic acid (DHA), may be advantageous because of their beneficial effects on human health. In addition, these fatty acids play an important role in reproductive processes in dairy cows. Our objective was to evaluate the protection of EPA and DHA against rumen biohydrogenation provided by $\mathrm{Ca}$ salts of fish oil. Four Holstein cows were assigned in a Latin square design to the following treatments: 1) ruminal infusion of Ca salts of fish oil and palm fatty acid distillate low dose (CaFO-1), 2) ruminal infusion of $\mathrm{Ca}$ salts of fish oil and palm fatty acid distillate high dose (CaFO-2), 3) ruminal infusion of fish oil high dose (RFO), and 4) abomasal infusion of fish oil high dose (AFO). The high dose of fish oil provided $\sim 16$ and $\sim 21 \mathrm{~g} / \mathrm{d}$ of EPA and DHA, respectively, whereas the low dose (CaFO-1) provided $50 \%$ of these amounts. A 10-d pretreatment period was used as a baseline, followed by 9-d treatment periods with interceding intervals of $10 \mathrm{~d}$. Supplements were infused every $6 \mathrm{~h}$, milk samples were taken the last $3 \mathrm{~d}$, and plasma samples were collected the last day of baseline and treatment periods. Milk fat content of EPA and DHA were 5 to 6 times greater with AFO, but did not differ among other treatments. Milk and milk protein yield were unaffected by treatment, but milk fat yield and DM intake were reduced by 20 and $15 \%$, respectively, by RFO. Overall, results indicate rumen biohy-
\end{abstract}

Received December 18, 2006.

Accepted May 3, 2007.

${ }^{1}$ Supported in part by Cornell Agricultural Experimental Station and Virtus Nutrition LLC. Research was also supported by Smith Lever funds from the Cooperative State Research, Education, and Extension Service, USDA, under Agreement No. NYC-127437. Any opinions, findings, conclusions, or recommendations expressed in this publication are those of the authors and do not necessarily reflect the view of the USDA.

${ }^{2}$ Current address: Balchem Encapsulates, New Hampton, NY 10958.

${ }^{3}$ Current address: Department of Animal Science, University of Vermont, Burlington 05405.

${ }^{4}$ Corresponding author: deb6@cornell.edu drogenation of long chain n-3 fatty acids was extensive, averaging $>85 \%$ for EPA and $>75 \%$ for DHA for the $\mathrm{Ca}$ salts and unprotected fish oil supplements. Thus, $\mathrm{Ca}$ salts of fish oil offered no protection against the biohydrogenation of EPA and DHA beyond that observed with unprotected fish oil; however, the Ca salts did provide rumen inertness by preventing the negative effects on DM intake and milk fat yield observed with unprotected fish oil.

Key words: calcium salts of fatty acids, fish oil, n-3 fatty acid, rumen protection

\section{INTRODUCTION}

There is growing interest in enhancing the intake of n-3 fatty acids, especially eicosapentaenoic acid (EPA; C20:5 n-3) and docosahexaenoic acid (DHA; C22:6 n-3), in lactating dairy cows. One reason relates to functional foods and a desire to increase the EPA and DHA content of dairy products; a high intake of these fatty acids was associated with reduced risk of several chronic diseases including coronary heart disease (Lock and Bauman, 2004). Increasing the EPA and DHA intake of dairy cows is also of interest because of possible beneficial effects on reproductive performance; an increase in n3 fatty acids may amplify the suppression of uterine $\mathrm{PGF}_{2 \alpha}$ synthesis, thereby potentially decreasing early pregnancy loses (Mattos et al., 2000). Dietary polyunsaturated fatty acids (PUFA) are extensively metabolized in the rumen, and this has a major impact on the profile of fatty acids available for absorption (Palmquist et al., 2005). Therefore, minimizing rumen biohydrogenation of PUFA is the major challenge in formulating dietary supplements that will enhance the postruminal supply of PUFA.

Wu and Papas (1997) reviewed the historical development of rumen-stable systems for the delivery of bioactive compounds in ruminant diets. They emphasized that the efficiency of the delivery system was dependent on the extent of the rumen protection and the postruminal bioavailability of the compound of interest. Several technologies are currently used to provide rumen protection for dietary supplements with Ca salts of fatty 
acids being most extensively utilized for lipid supplements. Although Ca salts of fatty acids are often referred to as being protected, Palmquist (2006) emphasized that this technology was not developed to protect unsaturated fatty acids against rumen biohydrogenation, but rather to render the fatty acids "ruminally inert with regard to their effects on the microbial population." Although EPA and DHA have not been specifically examined, studies with 18-carbon unsaturated fatty acids indicate the extent of protection by $\mathrm{Ca}$ salts will be affected by a number of factors including ruminal $\mathrm{pH}$ and degree of unsaturation and chain length of the fatty acids (Wu et al., 1991; Enjalbert et al., 1997).

The objective of the present study was to use Ca salts of fish oil and examine the protection against rumen biohydrogenation offered to EPA and DHA. Our approach to evaluate efficacy of this rumen protection method was to compare the transfer efficiency of EPA and DHA to milk fat observed when the supplement was added to the rumen vs. when it was abomasally infused. This approach was used recently to evaluate rumen protection methods for conjugated linoleic acid isomers (de Veth et al., 2005) and has the advantage that it provides an evaluation that accounts for both rumen protection and postruminal bioavailability.

\section{MATERIALS AND METHODS}

\section{Animals and Experimental Design}

All procedures involving cows were approved by the Cornell University Institutional Animal Care and Use Committee. Four multiparous Holstein cows (143 \pm 31 DIM) with rumen fistula were assigned to a $4 \times 4$ Latin square in which treatment supplements were 1) Ca salts of fish oil and palm fatty acid distillate low dose (CaFO-1), 2) Ca salts of fish oil and palm fatty acid distillate high dose (CaFO-2), 3) ruminal infusion of fish oil high dose (RFO), and 4) abomasal infusion of fish oil high dose (AFO). The Ca salt formulations and the fish oil were supplied by Virtus Nutrition Inc. (Corcoran, CA). A 10-d period before initiation of the experiment served as the baseline, followed by 9 -d treatment periods with a 10-d washout interval between treatments. The amount of fat and fatty acids provided by the treatments is presented in Table 1 . The CaFO-2, $\mathrm{RFO}$, and AFO supplements provided similar amounts of EPA $(\sim 16 \mathrm{~g} / \mathrm{d})$ and DHA $(\sim 21 \mathrm{~g} / \mathrm{d})$, whereas the CaFO1 supplement provided $50 \%$ of these amounts. Total daily dose was divided in 4 equal portions and infused every $6 \mathrm{~h}$ directly into the rumen or the abomasum. Abomasal infusion was via $0.5 \mathrm{~cm}$ (i.d.) polyvinyl chloride tubing that passed through the rumen fistula.

Cows were housed in individual stalls and fed a TMR diet formulated using the Cornell Net Carbohydrate
Table 1. Total amount of fatty acids provided by the lipid supplements

\begin{tabular}{lcr}
\hline Fatty acid, g/d & CaFO- $^{1}$ & Fish oil $^{2}$ \\
\hline $10: 0$ & 0.1 & $<0.1$ \\
$12: 0$ & 0.5 & 0.1 \\
$14: 0$ & 10.5 & 9.4 \\
$14: 1$ & 0.1 & 0.1 \\
$15: 0$ & 0.9 & 0.7 \\
$16: 0$ & 90.4 & 22.6 \\
$16: 1$ & 11.7 & 12.1 \\
$17: 0$ & 1.2 & 0.7 \\
$18: 0$ & 11.1 & 4.1 \\
$18: 1$ trans-6 to 8 & 0.1 & 0.1 \\
$18: 1$ trans-9 & 0.1 & $<0.1$ \\
$18: 1$ trans-11 & 1.8 & 2.2 \\
$18: 1$ trans-12 & $<0.01$ & 0.2 \\
$18: 1$ cis-9 - cis- 12 & 61.5 & 12.2 \\
$18: 2$ cis-9, & 15.3 & 1.6 \\
$18: 3$ & 0.8 & 0.3 \\
$20: 0$ & 3.3 & 3.1 \\
20.4 & 1.3 & 1.1 \\
EPA $^{3}$ & 16.6 & 16.2 \\
DPA & 3.7 & 3.8 \\
DHA & & 22.0 \\
Others & 21.2 & 32.4 \\
Total & 40.0 & 145 \\
\hline
\end{tabular}

${ }^{1}$ Values are for the Ca salts of fish oil and palm fatty acid distillate high dose (CaFO-2). Values for Ca salts of fish oil and palm fatty acid distillate low dose (CaFO-1) represent one-half of CaFO-2.

${ }^{2}$ Amounts provided by the fish oil supplement given by ruminal or abomasal infusion.

${ }^{3} \mathrm{EPA}=$ eicosapentaenoic acid, $20: 5$ all cis 5, 8, 11, 14, 17; DPA = docosapentaenoic acid, $22: 5$ all cis $7,10,13,16,19$; DHA = docosahexaenoic acid, 22:6 all cis 4, 7, 10, 13, 16, 19.

and Protein System (Fox et al., 2004) to meet or exceed their nutritional requirements. Cows were fed ad libitum allowing $10 \%$ refusals with fresh feed offered twice daily and orts recorded daily. Feed samples were taken the last $3 \mathrm{~d}$ of each treatment; composites were formed and analyzed by wet chemistry methods for $\mathrm{CP}, \mathrm{ADF}$, NDF and ether extract (Table 2; Dairy One Cooperative Inc., Ithaca, NY). Fresh water was available throughout the study.

Cows were milked at 0700 and $1900 \mathrm{~h}$ daily, and milk weights recorded; samples from each milking were stored at $4^{\circ} \mathrm{C}$ with preservative (bronopol tablet; D\&F Control System, San Ramon, CA) until analyzed for fat and true protein (Dairy One Cooperative Inc.) as described previously by Bernal-Santos et al. (2003). During the last $3 \mathrm{~d}$ of each treatment period, additional aliquots of milk were collected and immediately stored at $-20^{\circ} \mathrm{C}$ until analyzed for fatty acids.

On the last day of each treatment period following the morning milking, blood $(10 \mathrm{~mL})$ was obtained via coccigeal venipuncture and collected in vacuum tubes containing sodium heparin ( $100 \mathrm{U} / \mathrm{mL}$ of blood). Plasma was harvested by centrifugation $(2,800 \times g$ for $15 \mathrm{~min}$ at $4^{\circ} \mathrm{C}$ ) and stored at $-20^{\circ} \mathrm{C}$ until fatty acid analysis. 
Table 2. Ingredient and chemical composition of the diet

\begin{tabular}{lr}
\hline Dietary composition & \\
\hline Ingredient, \% of DM & \\
Grass hay & 40.80 \\
Cottonseed & 7.20 \\
Cracked corn & 21.58 \\
Bread meal & 4.91 \\
Wheat middlings & 6.40 \\
Gluten feed & 4.80 \\
Soybean meal (48\% CP) & 6.35 \\
Amino plus ${ }^{1}$ & 4.00 \\
Urea & 0.27 \\
Molasses & 0.71 \\
Limestone & 1.49 \\
Salt & 0.40 \\
Selenium & 0.05 \\
Trace mineral mix ${ }^{2}$ & 0.02 \\
Sodium sesquicarbonate & 0.89 \\
Magnesium oxide & 0.11 \\
Vitamin supplement & \\
Chemical analysis, $\%$ of DM & 0.02 \\
CP & 17.43 \\
Available protein & 16.68 \\
ADF & 24.98 \\
NDF & 41.93 \\
Ether extract & 4.88 \\
NE & Mcal/kg \\
\hline
\end{tabular}

\footnotetext{
${ }^{1} \mathrm{Ag}$ Processing Inc., Omaha, NE.

${ }^{2}$ The mix (DM basis) contained: $0.57 \% \mathrm{Ca}, 15.75 \%$ sulfur, and 1,360 ppm cobalt, 40,800 ppm copper, 2,700 ppm iodine, 10,200 ppm iron, $122,450 \mathrm{ppm}$ manganese, and $122,450 \mathrm{ppm}$ zinc.

${ }^{3}$ Vitamin supplement contained $165 \mathrm{IU} / \mathrm{g}$ of vitamin A, $30 \mathrm{IU} / \mathrm{g}$ of vitamin $\mathrm{D}$, and $750 \mathrm{IU} / \mathrm{g}$ of vitamin $\mathrm{E}$.

${ }^{4}$ Value does not include treatment supplements.
}

\section{Fatty Acid Analysis and Transfer Efficiency}

The extraction and methylation of milk fatty acids used the method of Hara and Radin (1978) and transmethylation as described by Bernal-Santos et al. (2003). Plasma fatty acids were extracted (Bligh and Dyer, 1959) and transmethylated according to the method described by Christie (1989). The fish oil used for abomasal and ruminal infusions contained the fatty acids esterified in triglycerides; these fatty acids were extracted and transmethylated as described for milk fat. The Ca salt supplements are formulated using free fatty acids; acid hydrolysis and ether extraction was used for these fatty acids (Dairy One Cooperative Inc.) as described by de Veth et al. (2006), and methylation utilized 1\% methanolic sulfuric acid (Christie, 1989).

Fatty acid methyl esters were quantified using a gas chromatograph (Hewlett Packard GCD system HP G1800 A, Avondale, PA) equipped with a CP-Sil 88 capillary column $(100 \mathrm{~m} \times 0.25 \mathrm{~mm}$ i.d. with $0.2-\mu \mathrm{m}$ film thickness; Varian Instruments, Walnut Creek, $\mathrm{CA}$ ). The oven temperature was set at $80^{\circ} \mathrm{C}$ for $3 \mathrm{~min}$, then increased to $190^{\circ} \mathrm{C}$ and maintained for $10 \mathrm{~min}$, with a final increase to $225^{\circ} \mathrm{C}$ held for $22 \mathrm{~min}$. Fatty acid peaks were identified using pure methyl ester stan- dards (NuChek Prep, Elysian, MN). A butter oil reference standard (CRM 164; Commission of the European Community Bureau of References, Brussels, Belgium) was analyzed periodically to control for column performance and as a check for the calculation of recoveries and correction factors for individual fatty acids.

Transfer efficiencies of EPA and DHA were calculated on an individual cow basis by subtracting the mean of the milk fat yield for each fatty acid during the last 3 $\mathrm{d}$ of baseline period from the mean during the last $3 \mathrm{~d}$ of each treatment period, and then dividing this number by the amount of each specific fatty acid provided by the treatment supplement.

\section{Statistical Analysis}

Milk production variables and milk fatty acid composition from last $3 \mathrm{~d}$ of treatment and plasma fatty acids from the last day of treatment were used for statistical analysis. Data were analyzed with PROC MIXED of SAS (SAS Institute, 2001); treatment and period were included in the model as fixed effects, and cow was included as a random variable. All data for 1 cow during 1 treatment period (RFO) were removed from the analysis because of clinical signs of mastitis.

\section{RESULTS AND DISCUSSION}

Milk yield and milk protein content and yield were not different among treatments. The CaFO-2 provided twice the amount of total fat than the other treatments, and this may explain the modest increase in milk fat yield compared with the CaFO-1 and AFO treatments. In contrast, the RFO treatment caused a reduction in milk fat content, milk fat yield, and DMI as compared with the treatments involving Ca salts of fish oil (Table 3). Decreased DMI was reported when diets were supplemented with unprotected fish oil (Shingfield et al., 2006), but DMI was unaffected when Ca salts of fish oil were fed (Allred et al., 2006). Polyunsaturated fatty acids can cause modifications in the rumen environment and changes in the microbial population that result in decreased fiber digestibility and a reduction in DMI (Doreau and Chilliard, 1997). Fotouhi and Jenkins (1992) proposed that feeding Ca salts of unsaturated fatty acids prevents drastic modifications of the rumen environment because the release of unsaturated fatty acids occurs slowly. As free unsaturated fatty acids are removed from the free fatty acid pool by biohydrogenation, Ca salts of PUFA will further dissociate to maintain the balance between dissociated and undissociated unsaturated fatty acids, thereby conferring rumen inertness as to effects on fiber digestion by this more gradual shift. 
Table 3. Production variables by treatment ${ }^{1}$

\begin{tabular}{lcccccc}
\hline & \multicolumn{7}{c}{ Treatment $^{2}$} & & \\
\cline { 2 - 5 } Variable & CaFO-1 & CaFO-2 & RFO & AFO & SEM & $P$-value \\
\hline DMI, kg/d & $21.9^{\mathrm{a}}$ & $22.1^{\mathrm{a}}$ & $18.5^{\mathrm{b}}$ & $21.0^{\mathrm{a}}$ & 1.36 & 0.01 \\
Milk yield, kg/d & 23.4 & 26.4 & 24.4 & 23.0 & 1.96 & 0.22 \\
Milk fat & & & & & & \\
\% & $3.76^{\mathrm{a}}$ & $3.61^{\mathrm{a}}$ & $2.76^{\mathrm{b}}$ & $3.56^{\mathrm{a}}$ & 0.13 & 0.002 \\
g/d & $868^{\mathrm{ab}}$ & $948^{\mathrm{a}}$ & $682^{\mathrm{c}}$ & $813^{\mathrm{b}}$ & 58 & 0.008 \\
Milk protein & 3.02 & 2.90 & 2.68 & 3.01 & 0.16 & 0.16 \\
\% & 690 & 758 & 652 & 690 & 46 & 0.22 \\
g/d & & & & & & \\
\hline
\end{tabular}

a-c Different superscripts represent differences among treatments $(P<0.05)$.

${ }^{1}$ Values represent least squares means of last $3 \mathrm{~d}$ of treatment.

${ }^{2}$ Cows received 1) ruminal infusion of Ca salts of fish oil and palm fatty acid distillate low dose (CaFO1), 2) ruminal infusion of $\mathrm{Ca}$ salts of fish oil and palm fatty acid distillate high dose (CaFO-2), 3) ruminal infusion of fish oil high dose (RFO), and 4) abomasal infusion of fish oil (AFO) high dose. The high dose provided 16.6 and $21.2 \mathrm{~g} / \mathrm{d}$ of eicosapentaenoic acid and docosahexaenoic acid, respectively, whereas the low dose provided $50 \%$ of these amounts.

The milk fatty acid profile during the last $3 \mathrm{~d}$ of the treatment period is presented in Table 4. The EPA and DHA were found in very low concentrations in milk fat; during the baseline period, EPA and DHA averaged only 0.04 and $0.02 \%$ of milk fatty acids, respectively. All treatments resulted in an increase in the milk fat content of EPA and DHA, and this was especially dramatic for the AFO treatment (an increase of 12 and 30 times baseline, respectively). The CaFO-1, CaFO-2, and RFO treatments were similar in milk fat content of EPA and DHA with concentrations representing about 20 to $25 \%$ of AFO. Changes in the milk fatty acid profile were observed for other fatty acids, especially with the RFO treatment where alterations included a marked increase in the proportion of total trans fatty acids and a reduction in stearic and oleic acids. Among trans18:1 fatty acids, the greatest change was observed in vaccenic acid (trans-11 18:1; 8 times greater) followed by trans-10 18:1 and trans-12 18:1. This is in agreement with reports from in vitro studies (Abughazaleh and Jenkins, 2004a,b) and in vivo studies involving unprotected fish oil supplements (Loor et al., 2005; Shingfield et al., 2006). Milk fat content of cis-9, trans-11 conjugated linoleic acid (CLA) was substantially increased with the RFO treatment and was modestly increased by CaFO-2. This was expected because vaccenic acid was increased in the milk fat when cows received the $\mathrm{RFO}$ and CaFO-2 treatments and the majority of cis9, trans-11 CLA in milk fat is synthesized endogenously from vaccenic acid as reviewed by Bauman and Lock (2006). Increases in cis-9, trans-11 CLA were reported with dietary supplements of fish oil and calcium salts of fish oil (e.g., Shingfield et al., 2003; Allred et al., 2006).

Treatment effects on the plasma fatty acid profile paralleled those observed for milk fat (Table 5). Abomasal infusion resulted in an increase in plasma concen- trations of EPA and DHA, and ruminal infusion of fish oil caused an increase in the proportion of trans-16:1, trans-10 18:1 plus trans-11 18:1, and cis-9, trans-11 CLA, and a substantial decrease in stearic acid.

The increase in trans isomers in milk fat and plasma fatty acids, and the reduction in milk fat yield observed with the RFO treatment reflect the modification of rumen microbial population and pathways of biohydrogenation typically caused by dietary supplements high in PUFA. These changes promote the formation and accumulation of unique biohydrogenation intermediates, some of which are potent inhibitors of milk fat synthesis (Bauman and Griinari, 2003). Although there was no reduction in milk fat or decrease in DMI when Ca salts of fish oil were fed, a moderate increase in the proportion of trans fatty acid isomers occurred in plasma and milk fat consistent with some dissociation and biohydrogenation of PUFA in the rumen.

Reports on the extent of rumen protection offered by Ca salts of 18-carbon unsaturated fatty acids indicate that ruminal biohydrogenation can be extensive, although there are differences among experiments. The degree of rumen protection conferred by $\mathrm{Ca}$ salts is correlated with rumen $\mathrm{pH}$ and fatty acids $\mathrm{pK}_{\mathrm{d}}$, and decreases as the extent of fatty acid unsaturation increases (Sukhija and Palmquist, 1990). Wu et al. (1991) calculated that the biohydrogenation of 18-carbon unsaturated fatty acids averaged $72 \%$ for an unprotected fat supplement compared with $56 \%$ for Ca salts of fatty acids for a different fat supplement. As the number of double bonds increased, however, the extent of ruminal biohydrogenation increased and the difference between unprotected and Ca-protected unsaturated fatty acids was reduced; for example, biohydrogenation of $18: 3$ averaged $84 \%$ for the unprotected supplement and $80 \%$ for the Ca-protected supplement. In a study with dairy 
Table 4. Fatty acid composition of milk fat ${ }^{1}$

\begin{tabular}{|c|c|c|c|c|c|c|}
\hline \multirow{2}{*}{$\begin{array}{l}\text { Fatty acid, g/100 g } \\
\text { of fatty acid }\end{array}$} & \multicolumn{4}{|c|}{ Treatment $^{2}$} & \multirow[b]{2}{*}{ SEM } & \multirow[b]{2}{*}{$P$-value } \\
\hline & CaFO-1 & CaFO-2 & $\mathrm{RFO}$ & $\mathrm{AFO}$ & & \\
\hline $4: 0$ & 4.21 & 4.33 & 3.83 & 4.10 & 0.23 & 0.22 \\
\hline $6: 0$ & $1.86^{\mathrm{b}}$ & $1.90^{\mathrm{ab}}$ & $1.75^{\mathrm{b}}$ & $2.05^{\mathrm{a}}$ & 0.08 & 0.02 \\
\hline $8: 0$ & $0.87^{\mathrm{b}}$ & $0.89^{\mathrm{b}}$ & $0.89^{\mathrm{b}}$ & $1.05^{\mathrm{a}}$ & 0.04 & 0.01 \\
\hline $10: 0$ & $1.62^{\mathrm{b}}$ & $1.61^{\mathrm{b}}$ & $1.87^{\mathrm{ab}}$ & $2.04^{\mathrm{a}}$ & 0.10 & 0.03 \\
\hline $12: 0$ & $1.80^{\mathrm{ab}}$ & $1.77^{\mathrm{b}}$ & $2.10^{\mathrm{ab}}$ & $2.19^{\mathrm{a}}$ & 0.11 & 0.05 \\
\hline $14: 0$ & 7.87 & 7.65 & 8.42 & 8.54 & 0.42 & 0.08 \\
\hline $14: 1$ cis -9 & 0.79 & 0.81 & 0.69 & 0.70 & 0.08 & 0.41 \\
\hline $15: 0$ & $0.69^{b}$ & $0.65^{\mathrm{b}}$ & $0.87^{\mathrm{a}}$ & $0.70^{\mathrm{b}}$ & 0.05 & 0.05 \\
\hline $16: 0$ & $25.92^{\mathrm{a}}$ & $25.92^{\mathrm{a}}$ & $23.60^{\mathrm{b}}$ & $23.72^{\mathrm{b}}$ & 0.90 & 0.02 \\
\hline $16: 1$ cis -9 & 1.62 & 1.63 & 1.56 & 1.80 & 0.09 & 0.30 \\
\hline $17: 0$ & $0.45^{\mathrm{b}}$ & $0.43^{\mathrm{b}}$ & $0.50^{\mathrm{a}}$ & $0.47^{\mathrm{ab}}$ & 0.02 & 0.03 \\
\hline $18: 0$ & $11.67^{\mathrm{a}}$ & $10.13^{\mathrm{a}}$ & $3.10^{\mathrm{b}}$ & $13.10^{\mathrm{a}}$ & 0.85 & 0.001 \\
\hline $18: 1$ trans -6 to 8 & $0.43^{\mathrm{cb}}$ & $0.53^{\mathrm{b}}$ & $0.78^{a}$ & $0.30^{\mathrm{c}}$ & 0.06 & 0.007 \\
\hline $18: 1$ trans -9 & $0.38^{\mathrm{b}}$ & $0.48^{\mathrm{b}}$ & $0.85^{\mathrm{a}}$ & $0.28^{b}$ & 0.07 & 0.005 \\
\hline $18: 1$ trans -10 & 0.57 & 0.67 & 1.27 & 0.41 & 0.27 & 0.19 \\
\hline $18: 1$ trans -11 & $1.54^{\mathrm{b}}$ & $2.22^{\mathrm{b}}$ & $18.33^{\mathrm{a}}$ & $1.28^{\mathrm{b}}$ & 0.94 & 0.001 \\
\hline $18: 1$ trans -12 & $0.64^{\mathrm{c}}$ & $0.84^{\mathrm{b}}$ & $2.00^{\mathrm{a}}$ & $0.42^{\mathrm{d}}$ & 0.04 & $<0.001$ \\
\hline $18: 1$ cis -9 & $27.32^{\mathrm{a}}$ & $26.40^{\mathrm{a}}$ & $9.21^{\mathrm{b}}$ & $25.63^{\mathrm{a}}$ & 1.18 & $<0.001$ \\
\hline $18: 2$ cis -9, cis -12 & $2.66^{\mathrm{b}}$ & $2.67^{\mathrm{b}}$ & $2.17^{\mathrm{c}}$ & $2.95^{\mathrm{a}}$ & 0.18 & 0.002 \\
\hline $18: 2$ cis -9, trans -11 & $0.70^{\mathrm{c}}$ & $1.04^{\mathrm{b}}$ & $6.05^{a}$ & $0.49^{c}$ & 0.11 & $<0.001$ \\
\hline $18: 3$ cis -9, cis -12, cis -15 & $0.36^{\mathrm{b}}$ & $0.37^{\mathrm{b}}$ & $0.26^{\mathrm{c}}$ & $0.51^{\mathrm{a}}$ & 0.03 & 0.003 \\
\hline 20:0 & $0.16^{\mathrm{a}}$ & $0.17^{\mathrm{a}}$ & $0.08^{\mathrm{c}}$ & $0.12^{\mathrm{b}}$ & 0.01 & $<0.001$ \\
\hline $\mathrm{EPA}^{3,4}$ & $0.10^{\mathrm{b}}$ & $0.11^{\mathrm{b}}$ & $0.14^{\mathrm{b}}$ & $0.55^{\mathrm{a}}$ & 0.05 & 0.001 \\
\hline $\mathrm{DPA}^{3}$ & $0.12^{\mathrm{b}}$ & $0.12^{\mathrm{b}}$ & $0.21^{\mathrm{b}}$ & $0.34^{\mathrm{a}}$ & 0.03 & 0.007 \\
\hline $\mathrm{DHA}^{3,4}$ & $0.11^{\mathrm{b}}$ & $0.14^{\mathrm{b}}$ & $0.20^{\mathrm{b}}$ & $0.63^{\mathrm{a}}$ & 0.06 & 0.002 \\
\hline & $5.40^{\mathrm{b}}$ & $6.35^{\mathrm{b}}$ & $9.33^{\mathrm{a}}$ & $5.41^{\mathrm{b}}$ & 0.29 & $<0.001$ \\
\hline \multicolumn{7}{|l|}{ Summation ${ }^{5}$} \\
\hline$<16$ carbons & $19.72^{\mathrm{b}}$ & $19.62^{\mathrm{b}}$ & $20.47^{\mathrm{ab}}$ & $21.37^{\mathrm{a}}$ & 0.72 & 0.04 \\
\hline 16 carbons & $27.54^{\mathrm{a}}$ & $27.55^{\mathrm{a}}$ & $25.20^{\mathrm{b}}$ & $25.52^{\mathrm{b}}$ & 0.97 & 0.04 \\
\hline$>16$ carbons & 47.35 & 46.48 & 44.93 & 47.70 & 1.54 & 0.22 \\
\hline
\end{tabular}

${ }^{\mathrm{a}-\mathrm{d}}$ Different superscripts represent differences among treatments $(P<0.05)$.

${ }^{1}$ Values represent least squares means of last $3 \mathrm{~d}$ of treatment.

${ }^{2}$ Cows received 1) ruminal infusion of Ca salts of fish oil and palm fatty acid distillate low dose (CaFO1), 2) ruminal infusion of Ca salts of fish oil and palm fatty acid distillate high dose (CaFO-2), 3) ruminal infusion of fish oil high dose (RFO), and 4) abomasal infusion of fish oil high dose (AFO). The high dose provided 16.6 and $21.2 \mathrm{~g} / \mathrm{d}$ of EPA and DHA, respectively, whereas the low dose provided half these amounts.

${ }^{3} \mathrm{EPA}=$ eicosapentaenoic acid, 20:5 all cis 5, 8, 11, 14, 17; DPA = docosapentaenoic acid, 22:5 all cis 7, 10, 13, 16, 19; DHA = docosahexaenoic acid, 22:6 all cis 4, 7, 10, 13, 16, 19.

${ }^{4}$ Mean for EPA and DHA during baseline period was 0.04 and $0.02 \mathrm{~g} / 100 \mathrm{~g}$ of fatty acids, respectively.

${ }^{5}$ Summation does not include fatty acids present at trace levels and listed above as others.

cows, Lundy et al. (2004) reported ruminal biohydrogenation of linoleic acid averaged $95 \%$ for unprotected soybean oil and $92 \%$ for the Ca salts of soybean oil. Harvatine and Allen (2006) supplemented Ca salts of unsaturated fatty acids and used a kinetic approach to estimate the extent of rumen biohydrogenation in lactating cows. They found that protection of the 18carbon PUFA from biohydrogenation was minimal in a commercial source of protected fat (Ca salts of fatty acids). Likewise in sheep, Fotouhi and Jenkins (1992) observed the extent of ruminal biohydrogenation of linoleic acid was $93 \%$ for free linoleic acid and $95 \%$ for Ca salts of linoleic acid.

There have been no in vivo investigations of the protection against ruminal biohydrogenation provided by Ca salts of longer chain PUFA ( $>18$-carbons) or Ca salts of fish oil. In addition, the aforementioned studies esti- mated the extent of biohydrogenation as the difference between the fatty acids originally supplied and the fatty acids recovered in the outflow from the rumen. To more completely evaluate protection, a comparison against unprotected fatty acids in the same lipid supplement is necessary, and ideally the comparison should account for differences in intestinal absorption to ensure that bioavailability was not altered by the protection method (Wu and Papas, 1997). The present study did this by utilizing EPA and DHA secreted into milk fat and comparing values observed with a rumen-protected supplement and during postruminal infusion of an unprotected supplement. No significant increases in EPA and DHA output in milk fat were observed for CaFO-2 compared with CaFO-1 (Table 6). In vitro studies suggest that increasing the dose of EPA and DHA may reduce the rate of ruminal biohydrogenation (Abughazaleh and 
Table 5. Fatty acid composition of plasma ${ }^{1}$

\begin{tabular}{|c|c|c|c|c|c|c|}
\hline \multirow{2}{*}{$\begin{array}{l}\text { Fatty acid, g/100 g } \\
\text { of fatty acid }\end{array}$} & \multicolumn{4}{|c|}{ Treatment $^{2}$} & \multirow[b]{2}{*}{ SEM } & \multirow[b]{2}{*}{$P$-value } \\
\hline & CaFO-1 & CaFO-2 & $\mathrm{RFO}$ & $\mathrm{AFO}$ & & \\
\hline $14: 0$ & 0.37 & 0.48 & 0.41 & 0.35 & 0.06 & 0.49 \\
\hline $15: 0$ & $0.34^{\mathrm{b}}$ & $0.33^{\mathrm{b}}$ & $0.43^{\mathrm{a}}$ & $0.34^{\mathrm{b}}$ & 0.01 & 0.009 \\
\hline $16: 0$ & $9.66^{\mathrm{ab}}$ & $9.96^{\mathrm{a}}$ & $9.28^{\mathrm{bc}}$ & $9.10^{\mathrm{c}}$ & 0.19 & 0.04 \\
\hline $16: 1$ cis -9 & 0.73 & 0.62 & 0.92 & 0.88 & 0.08 & 0.10 \\
\hline $16: 1$ trans & $0.21^{\mathrm{b}}$ & $0.25^{\mathrm{b}}$ & $0.66^{\mathrm{a}}$ & $0.23^{\mathrm{b}}$ & 0.04 & $<0.001$ \\
\hline $17: 0$ & 0.35 & 0.33 & 0.38 & 0.33 & 0.02 & 0.12 \\
\hline $18: 0$ & $14.50^{\mathrm{ab}}$ & $13.02^{\mathrm{b}}$ & $6.96^{\mathrm{c}}$ & $15.59^{\mathrm{a}}$ & 0.52 & $<0.001$ \\
\hline 18:1 trans -4 & $<0.01$ & 0.22 & 0.04 & $<0.01$ & 0.15 & 0.55 \\
\hline $18: 1$ trans -6 to 8 & 0.10 & 0.18 & 0.18 & 0.07 & 0.05 & 0.26 \\
\hline 18:1 trans -9 & 0.13 & 0.28 & 0.35 & 0.08 & 0.08 & 0.13 \\
\hline $18: 1$ trans -10 to 11 & $0.70^{\mathrm{b}}$ & $1.23^{\mathrm{b}}$ & $9.01^{\mathrm{a}}$ & $0.61^{\mathrm{b}}$ & 0.40 & $<0.001$ \\
\hline $18: 1$ trans -12 & $0.23^{\mathrm{c}}$ & $0.37^{\mathrm{b}}$ & $0.67^{\mathrm{a}}$ & $0.18^{\mathrm{c}}$ & 0.02 & $<0.001$ \\
\hline 18:1 trans -13 & $0.54^{\mathrm{c}}$ & $0.65^{\mathrm{b}}$ & $0.89^{\mathrm{a}}$ & $0.37^{\mathrm{d}}$ & 0.04 & $<0.001$ \\
\hline $18: 1$ cis -9 & $6.52^{\mathrm{a}}$ & $5.99^{\mathrm{ab}}$ & $5.19^{\mathrm{bc}}$ & $4.20^{\mathrm{c}}$ & 0.42 & 0.006 \\
\hline $18: 2$ cis -9, cis -12 & 49.69 & 47.50 & 44.64 & 44.32 & 2.15 & 0.11 \\
\hline $18: 2$ cis- 9 , trans -11 & $0.09^{\mathrm{b}}$ & $0.06^{\mathrm{b}}$ & $0.19^{\mathrm{a}}$ & $0.04^{\mathrm{b}}$ & 0.02 & 0.02 \\
\hline $18: 3$ cis -9, cis -12, cis -15 & 3.80 & 3.47 & 3.26 & 3.41 & 0.20 & 0.27 \\
\hline $18: 3$ cis -6, cis -9, cis -12 & $0.74^{\mathrm{a}}$ & $0.54^{\mathrm{b}}$ & $0.46^{\mathrm{b}}$ & $0.52^{\mathrm{b}}$ & 0.08 & 0.01 \\
\hline $20: 0$ & 0.06 & 0.07 & 0.03 & 0.05 & 0.01 & 0.10 \\
\hline $\mathrm{EPA}^{3,4}$ & $1.85^{\mathrm{b}}$ & $2.28^{\mathrm{b}}$ & $3.10^{\mathrm{b}}$ & $7.49^{\mathrm{a}}$ & 0.76 & 0.003 \\
\hline $\mathrm{DPA}^{3}$ & 0.59 & 1.72 & 0.95 & 0.88 & 0.73 & 0.53 \\
\hline $\mathrm{DHA}^{3,4}$ & $0.58^{\mathrm{b}}$ & $0.77^{\mathrm{b}}$ & $0.98^{\mathrm{b}}$ & $1.79^{\mathrm{a}}$ & 0.21 & 0.003 \\
\hline Others & 8.14 & 9.47 & 11.33 & 8.88 & 0.75 & 0.09 \\
\hline Total trans & $1.69^{\mathrm{b}}$ & $2.94^{\mathrm{b}}$ & $11.15^{\mathrm{a}}$ & $1.32^{\mathrm{b}}$ & 0.55 & $<0.001$ \\
\hline
\end{tabular}

${ }^{\mathrm{a}-\mathrm{d}}$ Different superscripts represent differences among treatments $(P<0.05)$.

${ }^{1}$ Values represent least squares means of last day of treatment.

${ }^{2}$ Cows received 1) ruminal infusion of Ca salts of fish oil and palm fatty acid distillate low dose (CaFO1), 2) ruminal infusion of $\mathrm{Ca}$ salts of fish oil and palm fatty acid distillate, high dose (CaFO-2), 3) ruminal infusion of fish oil high dose (RFO), and 4) abomasal infusion of fish oil high dose (AFO). The high dose provided 16.6 and $21.2 \mathrm{~g} / \mathrm{d}$ of EPA and DHA, respectively, whereas the low dose provided half these amounts.

${ }^{3} \mathrm{EPA}=$ eicosapentaenoic acid, 20:5 all cis 5, 8, 11, 14, 17; DPA = docosapentaenoic acid, 22:5 all cis 7, 10, 13, 16, 19; DHA = docosahexaenoic acid, 22:6 all cis 4, 7, 10, 13, 16, 19.

${ }^{4}$ Mean for EPA and DHA during baseline period was 0.76 , and $0.09 \mathrm{~g} / 100 \mathrm{~g}$ of fatty acid, respectively.

Table 6. Transfer of eicosapentaenoic (EPA) and docosahexaenoic (DHA) from fish oil to milk fat

\begin{tabular}{llllllll}
\hline & \multicolumn{5}{c}{ Treatment $^{1}$} & & \\
\cline { 2 - 5 } Variable & CaFO-1 & CaFO-2 & RFO & AFO & SEM & $P$-value \\
\hline Secretion, g/d & & & & & & \\
EPA $^{2}$ & $0.68^{\mathrm{b}}$ & $0.83^{\mathrm{b}}$ & $0.63^{\mathrm{b}}$ & $3.76^{\mathrm{a}}$ & 0.32 & 0.001 \\
DHA $^{2}$ & $0.78^{\mathrm{b}}$ & $1.06^{\mathrm{b}}$ & $0.95^{\mathrm{b}}$ & $4.30^{\mathrm{a}}$ & 0.41 & 0.002 \\
Transfer, $^{3} \%$ & & & & & & \\
EPA & $4.38^{\mathrm{b}}$ & $3.08^{\mathrm{b}}$ & $1.86^{\mathrm{b}}$ & $21.27^{\mathrm{a}}$ & 2.26 & 0.002 \\
DHA & $6.00^{\mathrm{b}}$ & $4.36^{\mathrm{b}}$ & $3.30^{\mathrm{b}}$ & $18.90^{\mathrm{a}}$ & 2.08 & 0.005 \\
\hline
\end{tabular}

${ }^{\mathrm{a}, \mathrm{b}}$ Different superscripts represent differences among treatments $(P<0.05)$.

${ }^{1}$ Cows received 1) ruminal infusion of Ca salts of fish oil and palm fatty acid distillate low dose (CaFO-1), 2) ruminal infusion of Ca salts of fish oil and palm fatty acid distillate high dose (CaFO-2), 3) ruminal infusion of fish oil high dose (RFO), and 4) abomasal infusion of fish oil high dose (AFO). The high dose provided 16.6 and $21.2 \mathrm{~g} / \mathrm{d}$ of EPA and DHA, respectively, whereas the low dose provided half these amounts.

${ }^{2} \mathrm{EPA}=20: 5$ all cis 5, 8, 11, 14, 17; DHA $=22: 6$ all cis 4, 7, 10, 13, 16, 19. Mean for EPA and DHA during the baseline period was 0.31 , and $0.14 \mathrm{~g} / \mathrm{d}$, respectively.

${ }^{3}$ Calculated as [(fatty acid in milk during last $3 \mathrm{~d}$ of treatment) (fatty acid in milk during baseline)] / [amount of fatty acid provided by supplement] $\times 100$.
Jenkins, 2004a). These differences, however, probably reflect the detrimental effects of high doses of PUFA on the rumen microorganisms, and this would be minimized with the use of Ca salts of fatty acids. The 2 doses of Ca salts of fish oil averaged 3.7 and $5.1 \%$ transfer of EPA and DHA to milk fat, respectively (Table 6). These values were similar to the 2 and $4 \%$ transfer for EPA and DHA observed with dietary supplements of fish oil or ruminal infusion of unprotected fish oil (Jones et al., 2000; Chilliard et al., 2001).

Abomasal infusion of fatty acids is a convenient experimental method to avoid rumen biohydrogenation. Thus, the difference in fatty acid output in milk between abomasal infusion and other treatments can be attributed to metabolism in the rumen, intestinal bioavailability, or both. The transfer of abomasally infused EPA and DHA to milk fatty acids was 21.3 and $18.9 \%$, respectively. These values are similar to those reported by others (Lock and Bauman, 2004). Transfer efficiencies of EPA and DHA are lesser than those observed for 18-carbon unsaturated fatty acids, where transfer in established lactation ranges from 30 to $70 \%$ as reviewed by Chilliard et al. (2000). The transfers of EPA and 


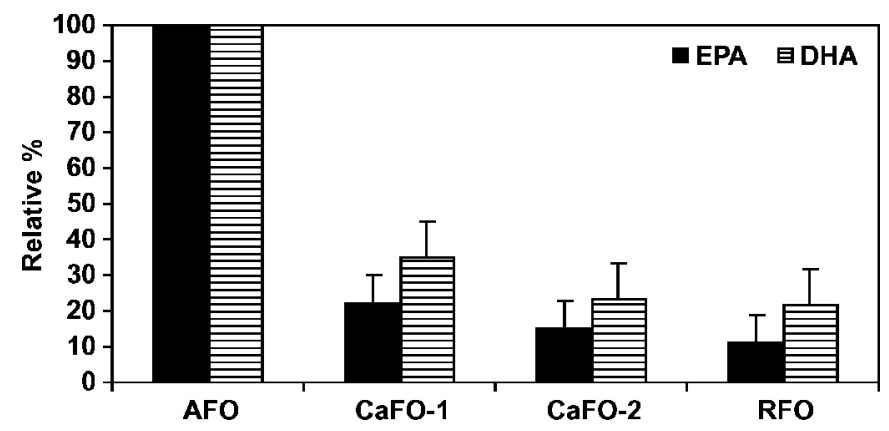

Figure 1. Transfer of eicosapentaenoic acid (EPA) and docosahexaenoic acid (DHA) in fish oil supplements to milk fat as compared with abomasal infusion (corresponding to $100 \%$ rumen protection). Cows received 1) ruminal infusion of Ca salts of fish oil and palm fatty acid distillate low dose (CaFO-1), 2) ruminal infusion of Ca salts of fish oil and palm fatty acid distillate high dose (CaFO-2), 3) ruminal infusion of fish oil high dose (RFO), and 4) abomasal infusion of fish oil high dose (AFO). The high dose provided 16.6 and $21.2 \mathrm{~g} / \mathrm{d}$ of EPA and DHA, respectively, whereas the low dose provided $50 \%$ of these amounts.

DHA to milk fat for the Ca salts of fish oil and the rumen infused fish oil treatments are compared relative to abomasal infusion in Figure 1. With the same dose of EPA and DHA supplemented as a Ca salt (CaFO-2), transfer to milk was only 14 and $23 \%$, respectively, of that observed with abomasal infusion. Likewise, transfer efficiency with the ruminal infusion of fish oil was 9\% for EPA and $17 \%$ for DHA. Thus, the rumen biohydrogenation of EPA and DHA was extensive for the $\mathrm{Ca}$ salts and the unprotected fish oil supplements, and the Ca salts of fish oil fatty acids provided no protection of EPA and DHA from rumen biohydrogenation beyond that seen with the unprotected fish oil supplement.

\section{CONCLUSIONS}

Supplementation with unprotected fish oil resulted in decreased DMI and a reduction in milk fat yield. These effects were not observed with Ca salts, indicating that this method offers protection from the adverse effects of unsaturated fatty acids on rumen digestion. The benefits of $\mathrm{Ca}$ salts, however, did not extend to protection of EPA and DHA from rumen biohydrogenation. Abomasal infusion of fish oil resulted in a considerable increase in the proportion of EPA and DHA in plasma and milk, but there was no difference in secretion of these fatty acids among other treatments indicating a similar degree of biohydrogenation for EPA and DHA in unprotected fish oil and Ca salts of fish oil. The changes observed in the milk fatty acid profile with RFO were indicative of alterations in rumen pathways of biohydrogenation and correspond to those reported by others in situations of diet-induced milk fat depression. Overall, results demonstrate that Ca salts of fish oil provided rumen inertness with regard to adverse effects on DMI and milk fat yield, but provided no protection against biohydrogenation of EPA and DHA in the rumen. Thus, with Ca salts or unprotected fish oil supplements, the postruminal supply of EPA and DHA is a function of the limited proportion of these fatty acids that escapes rumen biohydrogenation.

\section{ACKNOWLEDGMENTS}

The authors would like to acknowledge the collaboration of Dan Luchini (Adisseo USA Inc., Alpharetta, GA) in implementing the study. The assistance of the following students and staff at Cornell University is appreciated: Kevin Harvatine, James Perfield, Antonio García, Warren Waybright, Stephen Tucker, William English, and Gladys Birdsall.

\section{REFERENCES}

Abughazaleh, A. A., and T. C. Jenkins. 2004a. Disappearance of docosahexaenoic and eicosapentaenoic acids from cultures of mixed ruminal microorganisms. J. Dairy Sci. 87:645-651.

Abughazaleh, A. A., and T. C. Jenkins. 2004b. Short communication: Docosahexaenoic acid promotes vaccenic acid accumulation in mixed ruminal cultures when incubated with linoleic acid. J. Dairy Sci. 87:1047-1050.

Allred, S. L., T. R. Dhiman, C. P. Brennand, R. C. Khanal, D. J. McMahon, and N. D. Luchini. 2006. Milk and cheese from cows fed calcium salts of palm and fish oil alone or in combination with soybean products. J. Dairy Sci. 89:234-248.

Bauman, D. E., and J. M. Griinari. 2003. Nutritional regulation of milk fat synthesis. Annu. Rev. Nutr. 23:203-227.

Bauman, D. E., and A. L. Lock. 2006. Conjugated linoleic acid: Biosynthesis and nutritional significance. Pages 93-135 in Advanced Dairy Chemistry Vol. 2: Lipids. P. F. Fox and P. L. H. McSweeney, ed. Springer, New York, NY.

Bernal-Santos, G., J. W. Perfield, D. M. Barbano, D. E. Bauman, and T. R. Overton. 2003. Production responses of dairy cows to dietary supplementation with conjugated linoleic acid (CLA) during the transition period and early lactation. J. Dairy Sci. 86:3218-3228.

Bligh, E. G., and W. J. Dyer. 1959. A rapid method of total lipid extraction and purification. Can. J. Biochem. Physiol. 37:911-917.

Chilliard, Y., A. Ferlay, and M. Doreau. 2001. Effect of different types of forages, animal fat or marine oils in cow's diet on milk fat secretion and composition, especially conjugated linoleic acid (CLA) and polyunsaturated fatty acids. Livest. Prod. Sci. 70:31-48.

Chilliard, Y., A. Ferlay, R. M. Mansbridge, and M. Doreau. 2000. Ruminant milk fat plasticity: Nutritional control of saturated, polyunsaturated, trans and conjugated fatty acids. Ann. Zootech. 49:181-205.

Christie, W. W. 1989. Gas Chromatography and Lipids: A Practical Guide. The Oily Press, Ayr, UK.

de Veth, M. J., E. Castañeda-Gutiérrez, D. A. Dwyer, A. M. Pfeiffer, D. E. Putman, and D. E. Bauman. 2006. Response to conjugated linoleic acid in dairy cows differing in energy and protein status. J. Dairy Sci. 89:4620-4631.

de Veth, M. J., S. K. Gulati, N. D. Luchini, and D. E. Bauman 2005. Comparison of calcium salts and formaldehyde-protected conjugated linoleic acid in inducing milk fat depression. J. Dairy Sci. 88:1685-1693.

Doreau, M., and Y. Chilliard. 1997. Effects of ruminal or postruminal fish oil supplementation on intake and digestion in dairy cows. Reprod. Nutr. Dev. 37:113-124. 
Enjalbert, F., M. C. Nicot, C. Bayourthe, M. Vernay, and R. Moncoulon. 1997. Effects of dietary calcium soaps of unsaturated fatty acids on digestion, milk composition and physical properties of butter. J. Dairy Res. 64:181-195.

Fotouhi, N., and T. C. Jenkins. 1992. Ruminal biohydrogenation of linoleoyl methionine and calcium linoleate in sheep. J. Anim. Sci. 70:3607-3614.

Fox, D. G., L. O. Tedeschi, T. P. Tylutki, J. B. Russell, M. E. Van Amburgh, L. E. Chase, A. N. Pell, and T. R. Overton. 2004. The Cornell Net Carbohydrate and Protein System model for evaluating herd nutrition and nutrient excretion. Anim. Feed Sci. Technol. 112:29-78.

Hara, A., and N. S. Radin. 1978. Lipid extraction of tissues with a low-toxicity solvent. Anal. Biochem. 90:420-426.

Harvatine, K. J., and M. S. Allen. 2006. Fat supplements affect fractional rates of ruminal fatty acid biohydrogenation and passage in dairy cows. J. Nutr. 136:677-685.

Jones, D. F., W. P. Weiss, and D. L. Palmquist. 2000. Short communication: Influence of dietary tallow and fish oil on milk fat composition. J. Dairy Sci. 83:2024-2026.

Lock, A. L., and D. E. Bauman. 2004. Modifying milk fat composition of dairy cows to enhance fatty acids beneficial to human health. Lipids 39:1197-1206.

Loor, J. J., A. Ferlay, A. Ollier, K. Ueda, M. Doreau, and Y. Chilliard. 2005. High-concentrate diets and polyunsaturated oils alter trans and conjugated isomers in bovine rumen, blood, and milk. J. Dairy Sci. 88:3986-3999.

Lundy, F. P., E. Block, W. C. Bridges, J. A. Bertrand, and T. C. Jenkins. 2004. Ruminal biohydrogenation in Holstein cows fed soybean fatty acids as amides or calcium salts. J. Dairy Sci. 87:1038-1046.

Mattos, R., C. R. Staples, and W. W. Thatcher. 2000. Effects of dietary fatty acids on reproduction in ruminants. Rev. Reprod. 5:38-45.

Palmquist, D. L. 2006. Milk fat: Origin of fatty acids and influence of nutritional factors thereon. Pages 43-91 in Advanced Dairy Chemistry Vol. 2: Lipids. P. F. Fox and P. L. H. McSweeney, ed. Springer, New York, NY.

Palmquist, D. L., A. L. Lock, K. J. Shingfield, and D. E. Bauman. 2005. Biosynthesis of conjugated linoleic acid in ruminants and humans. Adv. Food Nutr. Res. 50:179-218.

SAS User's Guide. Statistics, Version 8. 2001. SAS Inst., Inc., Cary, NC.

Shingfield, K. J., S. Ahvenjarvi, V. Toivonen, A. Arola, K. V. V. Nurmela, P. Huhtanen, and J. M. Griinari. 2003. Effect of dietary fish oil on biohydrogenation of fatty acids and milk fatty acid content in cows. Anim. Sci. 77:165-179.

Shingfield, K. J., C. K. Reynolds, G. Hervas, J. M. Griinari, A. S Grandison, and D. E. Beever. 2006. Examination of the persistency of milk fatty acid composition responses to fish oil and sunflower oil in the diet of dairy cows. J. Dairy Sci. 89:714-732.

Sukhija, P. S., and D. L. Palmquist. 1990. Dissociation of calcium soaps of long-chain fatty acids in rumen fluid. J. Dairy Sci. 73:1784-1787.

Wu, S. H. W., and A. Papas. 1997. Rumen-stable delivery systems. Adv. Drug Deliv. Rev. 28:323-334.

Wu, Z., O. A. Ohajuruka, and D. L. Palmquist. 1991. Ruminal synthesis, biohydrogenation and digestibility of fatty acids by dairy cows. J. Dairy Sci. 74:3025-3034. 